\title{
Analysis of the Legal Basis to Mitigate Cyberbullying in Social Networks in Ecuador
}

\author{
Segundo Moisés Toapanta Toapanta ${ }^{\mathrm{a},{ }^{*}}$, Ingrid Lilibeth Tacuri López ${ }^{\mathrm{a}}$, Luis Enrique \\ Mafla Gallegos ${ }^{\mathrm{b}}$ \\ a Department Computer Science, Salesian Polytechnic University of Ecuador (UPS), \\ Chambers 227 and June 5, Ecuador \\ ${ }^{\mathrm{b}}$ Faculty of Systems Engineering, National Polytechnic School (EPN), Ladrón de \\ Guevara E11-253, Ecuador
}

\begin{abstract}
Cyberbullying is a critical issue in society worldwide, however in Ecuador is not given necessary importance to mitigate this cybercrime. It has been proposed to develop an exhaustive analysis of the laws that are currently considered to sanction cyberbullying when denouncing this fact. The deductive method and exploratory research were employed to make the analysis of the information consulted from the various sources that are obtained on the network about the topic discussed. The investigation revealed how cyberbullying cases arise, from which it is obtained that only $0.07 \%$ have been reported, with this result it can be deduced that the number of reported cases is very low in relation to the total number of cellphones activated in Ecuador and people who may be victims of this cyber-crime. In addition, a "Criminal Process Diagram" was obtained that determines the sequence of how the judicial process work. The applied method resulted the following: Can be created a law project that battles each type of derived cyberbullying. It was concluded that several institutions in Ecuador work together with organizations to prevent cyberbullying, however, when this happens, the laws are not enough to punish the act.
\end{abstract}

Keywords. Cyberbullying, risk, social networks, laws, mitigation.

\section{Introduction}

Digital bullying includes bullying through instant messaging, postings, emails, SMS or creating a website that makes fun of someone through images; also refers to being treated in a hurtful or unpleasant way via mobile phones or online; as well as the appropriation and publication of inappropriate or unflattering photographs [1].

Although social networking websites provide many benefit to users, cyber criminals can use these websites to commit different types of bad behavior and/or aggressive behavior [2], take advantage of the opportunities offered by the information revolution and social networks to communicate and engage in illegal underground activities, such as online fraud, cyberpredation, cyberbullying [3].

\footnotetext{
* Corresponding Author: Segundo Moisés Toapanta Toapanta, E-mail: stoapanta@ups.edu.ec
} 
Taking advantage of the accelerated advance of information and communication technologies (ICT), cyberbullying is presented, which is the harassment that a person suffers through messages, photographs, memes, through social networks such as Facebook, Whatsapp, Twitter, Snapchat, becoming viral, every time it reaches a user, multiplying also, the psychological damages that this type of violence causes, that have been the cause of negative effects such as: low self-esteem, poor academic performance, exclusion, depression, and until the victim's death [4].

According to United Nations Children's Fund (UNICEF), more than 175,000 children connect to the Internet every day for the first time, one new child every halfsecond, becoming the most vulnerable to a range of risks and damages, "including access to harmful content, sexual exploitation and abuse, cyberbullying and misuse of their private information" [5]. The experts say that young people end up feeling the real impact when photographs and online rumors about them spread at their social environment [6].

This starts primarily because people currently have no control over what is posted on the net, most teens post on their social media photos with implicit information that cyber criminals use to stalk virtually, Even parents with no intention of causing discomfort in their children publicly share photos and videos that can generate being targeted by these social attacks. The Internet is within the reach of children and they curiously navigate the Web without limit finding platforms disguised as games that invite them to exchange sensitive information or photos to get a reward or to raise a level in the game turns into manipulation.

How is cyberbullying mitigated on Social Networks in Ecuador?

It's important to reduce the risk of tolerating the different types of harassment that occur via the Internet, for which several public and private companies/organizations have collaborated together through social media campaigns, TV, schools and colleges to prevent more people, mainly children, from falling victim to this social harassment. Internet and social media networks such as Facebook and Twitter have recently made policy and privacy changes to ensure safe user experience. However, the effectiveness of these tools and efforts in curbing abuse and cyberbullying needs constant monitoring and research [7].

Ecuador has laws that contain two articles that were adapt to the crime and allow a complete investigation of cyber bullying so that appropriate measures can be taken in response to this offense. These articles correspond to 173 and 174 stipulated in the Comprehensive Organic Criminal Code (COIP) that contains the existing legislation to protect the rights of individuals and among other articles and news that will be analyzed in the development of this section as a current solution to mitigate the risks of information that freely provided through the internet.

The Government does not have a security policy that protects society from the problems brought about by the advance of technology, insecurity on social networks is becoming more evident, users are easy prey and information can be vulnerable to more constant risks. Public bodies must apply a model that mitigates risks and technological threat and that has a vision of the future of data protection [8].

The information and articles reviewed are:

El ciberacoso es un problema en crecimiento que afecta hasta 1 de cada 10 niños en el mundo [1], Predicting Cyberbullying on Social Media in the Big Data Era Using Machine Learning Algorithms: Review of Literature and Open Challenges [2], WordnetBased Criminal Networks Mining for Cybercrime Investigation [3], Cyberbullying: una realidad de intimidación en las unidades [4], Telefónica Movistar: La realidad del ciberacoso en Ecuador y cómo denunciarlo [5], Cómo prevenir el ciberacoso o 
ciberbullying [6], Cyberbullying on social media platforms among university students in the United Arab Emirates [7], Impact on the Information Security Management due to the Use of Social Networks in a Public Organization in Ecuador [8], How students react to different cyberbullying events: Past experience, judgment, perceived seriousness, helping behavior and the effect of online disinhibition [9], Exposure to cyberbullying in WhatsApp classmates' groups and classroom climate as predictors of students' sense of belonging: A multi-level analysis of elementary, middle and high schools [10], Investigating the mechanisms of theory of planned behavior on Cyberbullying among Thai adolescents [11], Cyberbullying victimization at work: Social media identity bubble approach [12], Tecnologías de la Información y Comunicaciones [13], Ciberacoso, un dolor de cabeza para los padres [14], Moral disengagement and adolescents' cyberbullying perpetration: Student-student relationship and gender as moderators [15], National Institute of Statistics and Censuses (INEC) [16].

Exploratory research is used in different sources of information and the deductive method to analyze the information found.

It turns out that in Ecuador the laws condemn the fact of having a sexual encounter with a minor through some electronic means but not penalizing the crime of cyberbullying, which are different concepts, but when this happens the legal entities adapt these laws to punish this crime. For this, it is proposed to create a bill that includes articles that penalize the crime of cyberbullying in its different settings.

It can be concluded that the laws in Ecuador are not yet prepared to mitigate cases of cyberbullying in all its scenarios.

\section{Materials and Methods}

The exploratory research and deductive method used for the development of this article are selected to analyze the information found and obtain results.

\subsection{Materials}

A web research was carried out, news was consulted in newspapers, scientific journals, digital articles, theses, etc that make references to the topic in question. The information of articles consulted were the following:

Technology has gone considerably beyond the cultural boundaries of communication, has transcended in a globalized way and sometimes even aggressive or violent, we can visualize it online, this leads to the misuse of technology in social media platforms, for this reason it is a priority to review the improper use of users when consuming these sites [2]. A study was conducted through a web page with interviews voluntarily, anonymously and confidentially to evaluate the judgment, behavior and experience of students considering three scenarios: harassment, denigration and exclusion. Results varied by gender, boys were more likely to intimidate and girls recognized the behavior that causes bullying [9]. In Israel today, the most used application is Whatsapp, a large part of children and adolescents occupy this service to establish immediate communication and share content, Part of this content is used to harass another person through this same app and between groups of common friendships generating cyber bullying. This harassment is then taken to the real social environment and can seriously harm the victim [10]. Educational units have an important role in the cultural contribution of the technological development of their target groups so that they 
are not victims of cyberbullying, promote clear objectives on the use of social networks that are increasingly used by minors by promoting practices of respect and solidarity, interactive talks among students about cyberbullying and thus prevent computer violence [4]. The behavior of users in the network has a major impact on the development of cyberbullying, so that this does not happen, the family structure is very determinant in this aspect to raise self-esteem, play a leading role and users do not easily descend into intimidation. This should include activities that raise the self-esteem of their leaders and can be managed in an efficient and appropriate manner [11].

In another scenario there is also exists cyberbullying at work that cyberbullying at work adopts aggressive and threatening behaviour including social ostracism. One study analyzed the risks and factors associated with cyberbullying at work, in addition to its impact on well-being. For the study they took surveys of employees of expert organizations and national samples. The results reveal that $13 \%$ and $17 \%$ respectively of the victims were young people and active users in the bubbles of identity, these showed greater psychological distress, exhaustion and technical stress [12].

Cyberbullying is a type of violence in which people who commit bullying cannot be detected, or whether it is an act of an individual or a group of individuals cannot be determined [11]. Online social networks provide offenders with tools for aggressive actions and networks for committing misconduct. Therefore, methods addressing both aspects (content and network) should be optimized to detect and limit aggressive behavior in complex systems [2].

In Ecuador, there are no exact figures for cyberbullying because the majority of people who are victims of this crime do not report to the Office of the Public Prosecutor, However, United Nations Children's Fund (UNICEF) conducted the NATIONAL SCHOOL BULLYING SURVEY of different groups of people in 2019 to ascertain the status of this problem. From the results of this survey we have obtained data that are relevant to continue the analysis of this topic represented in the following graph:

\section{REPORT OF HARASSMENT IN ECUADOR}

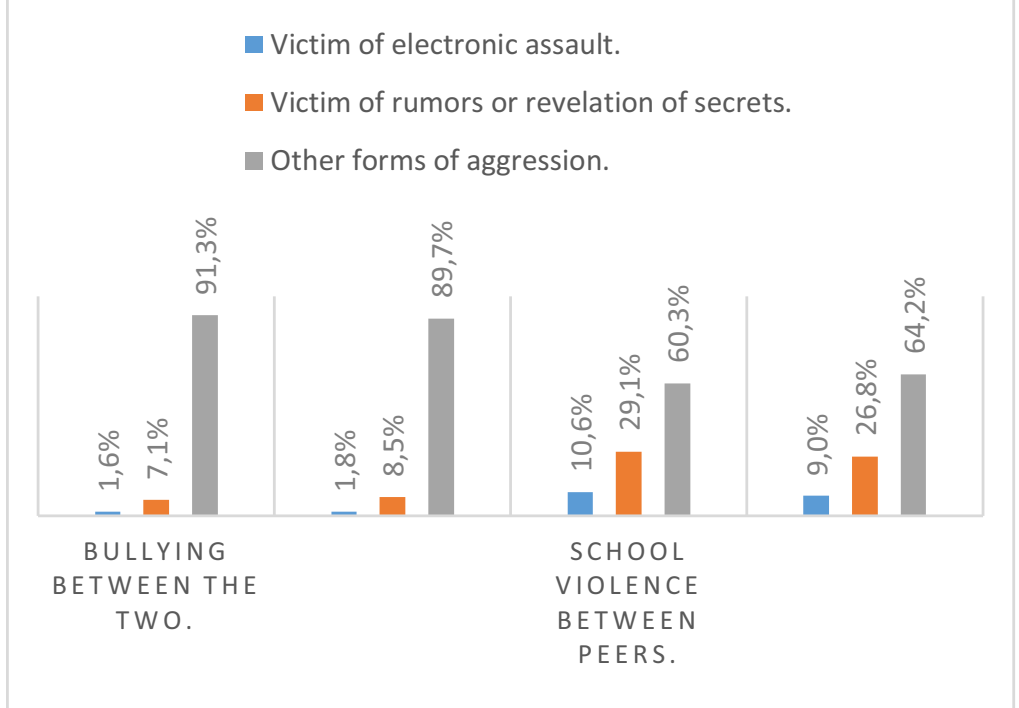

Figure 1. Report on bullying in Ecuador. United Nations Children's Fund (Unicef) - Results of the National Survey of School Bullying in 2020. 
National figures published on the page of the National Institute of Statistics and Censuses (INEC) are also analyzed with information related to the subject in question where the percentage of the population that uses the cell phone and social networks can be seen, as well as figures based on the report "Ecuador Digital State" that correspond to the number of users per social network.

The Organic Law for the Prevention, Control and Punishment of Harassment, Intimidation or Violence in the Study Centers of Ecuador (Bullying) was considered to mitigate cyberbullying in social networks.

In Art. 173 and Art. 174 of the Comprehensive Organic Criminal Code (COIP) refer to acts of a sexual nature committed through electronic means, which are punished only when the victims are minors, However, consideration must be given to persons over the age of 18 who are not exempt from such behavior, and who today have been victimized by the commission of such acts and the lack of regulations.

\subsection{Methods}

Three phases were used to analyze this topic.

The first phase included searching for information in digital newspapers in Ecuador, databases of scientific journals and conference articles indexed to Scopus because it is the database with the largest collection of articles worldwide.

In the second phase we take information in figures that we find in digital newspapers and institutions such as National Statistics and Census Institute (INEC) of people who use the internet, social networks in Ecuador to make a statistical analysis of the current situation, in addition, to the most frequent forms of aggression in the country to focus on aggression by electronic means. Additionally, information related with this topic at the international level was considered for be able to compare the problematic.

The third phase consisted of seeking information on how this fact is mitigated in Ecuador.

To begin our statistical analysis, first analyzed the groups of people who use the internet with the following information provided by National Statistics and Census Institute (INEC) of Ecuador, this institution is the charged of analyzing economic, sociodemographic, and environmental data generated by the obtaining information through censuses, population surveys, and data from other institutions for decisionmaking in the country through the National Statistical System (SEN):

In addition, until December 2017 the percentage of people who used the internet according to ages are: from 5 to 15 years old is $50.4 \%$; from 16 to 24 years old is $85.2 \%$; from 25 to 34 years old is $73.9 \%$; from 35 to 44 years old is $59.6 \%$; from 45 to 54 years old is $44.0 \%$; from 55 to 64 years old is $27.2 \%$; 65 years old or older is $7.8 \%$. $74.7 \%$ of Ecuadorians used the internet for less than once a day [13]. It was deduced that more than $59 \%$ of Ecuadorians between 16 and 44 years old accessed and continuously used the internet to obtain information, general communication, education, learning and others [8].

The use of social networks in Ecuador was then analyzed, this analysis was obtained from the figures presented by National Statistics and Census Institute (INEC) on its website. These graphs helped us to know basic and important information to continue with the development of the topic of this article. 


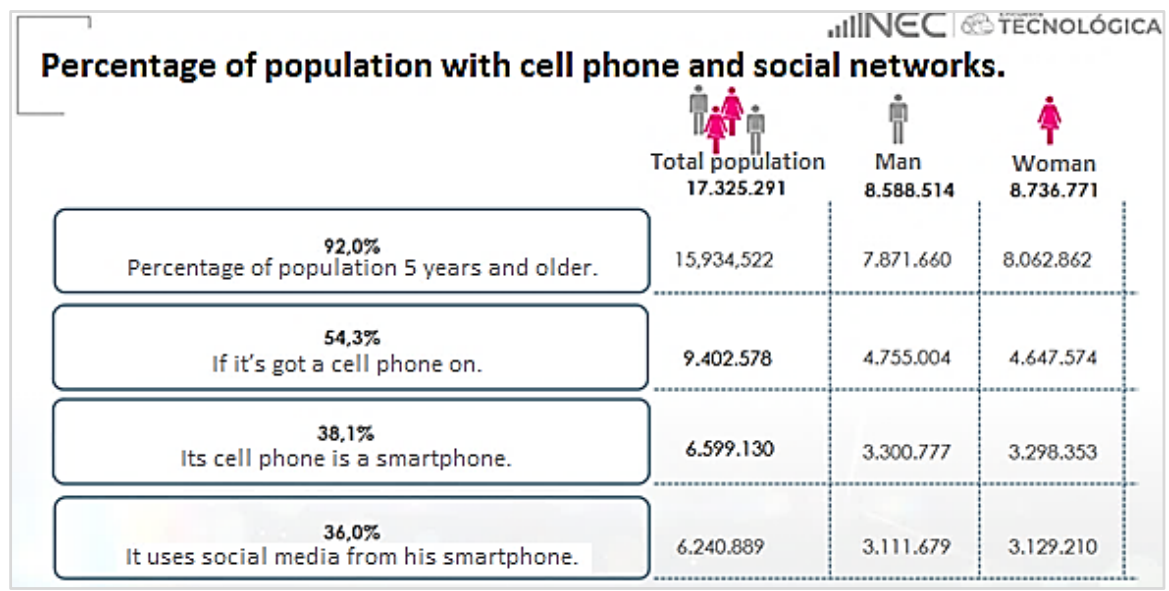

Figure 2. Percentage of population with cell phone and social networks from 2012 to 2018 provided by INEC.

As can be seen from figure 2, according to the figures from 2012 to 2018 given by National Statistics and Census Institute (INEC), the percentage of the population that used social networks is quite high, this percentage took as reference people from 5 years old onwards who made use of social networks from their cell phones, these cell phones in their great majority had internet access at some point in the day. Of the total population surveyed, 17,325,291 people, of whom $92 \%$ had cell phones, however, only $38.1 \%$ were Smartphones, which means that they have the technology to access the internet, of which $36 \%$ made use of social networks, it was possible to interpret that $2.1 \%$ did not use social networks either because they did not have access to the internet or because they had no interest in using these social applications.

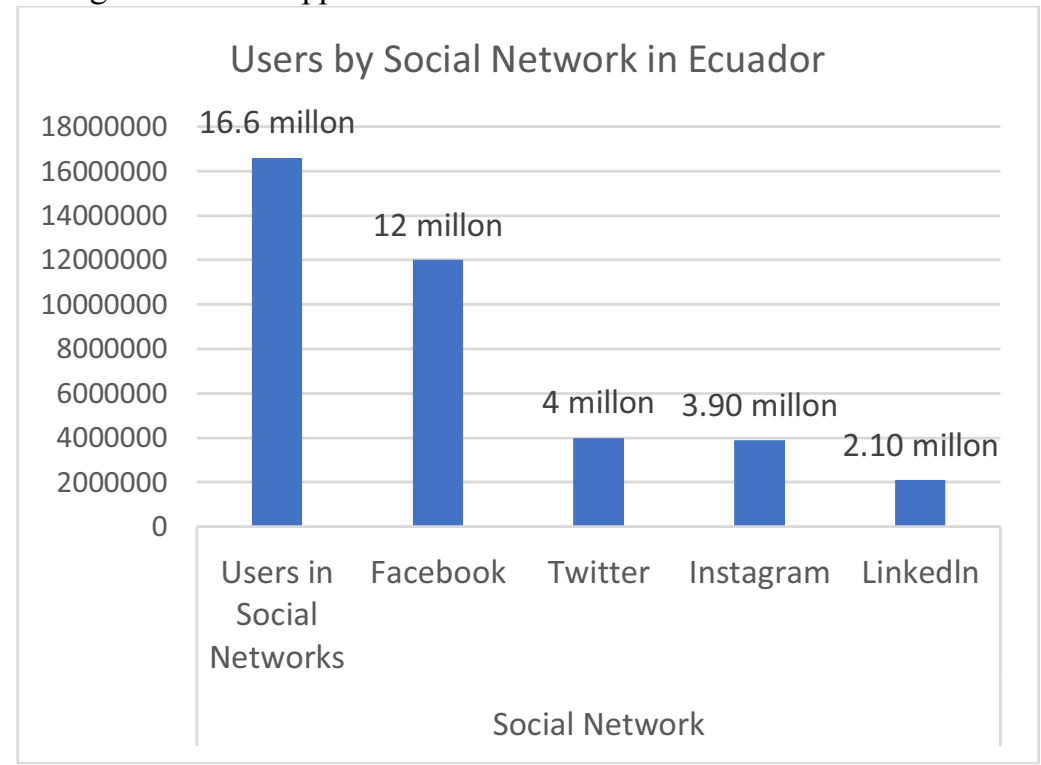

Figure 3. Figures based on the Ecuadorian Digital State report on Ecuador until January 2019. 
This figure, compiled with figures based on the report, analyzed the visits of 16.6 million people in Ecuador to the main social networks until January 2019. As could be evidenced until this date there were approximately 12 million users who used Facebook, leading in Ecuador and surpassing notably Twitter and Instagram, this will help us interpret analytical results later.

In the first chart, information presented by National Statistics and Census Institute (INEC) on its web platform was analyzed, the percentage of people who used social networks in their cell phone from 2012 to 2018 was identified, and it was possible to show that this percentage mostly includes minors. Within the range of this percentage, National Statistics and Census Institute (INEC), in its report of the Digital State of Ecuador, compiled a second graph of the figures obtained from social media users with the census of 16.6 million inhabitants until 2019, this information was analyzed in percentages and showed that Facebook leads in Ecuador, being this social network the highest risk in this country because users are of all ages. Whatsapp, the most widely used messaging application in Latin America, has been excluded from these charts.

From this analysis of figures, we obtained the two most commonly used applications in Ecuador, with which we proceeded to investigate in online newspapers all the information related to these apps and cyberbullying. The aim of this research was to find out how it affects the social life of users.

Having knowledge of this information are proceeded to look for laws in Ecuador that mitigate this cybercrime, two articles stipulated in the COIP that currently punish these social cybercrimes with custodial punishment were analyzed.

Article 173 establishes a prison term of one to three years for "a person who, by electronic or telematic means, proposes to arrange a meeting with a person under the age of 18, provided that the proposal is accompanied by material acts aimed at bringing him or her closer together for sexual or erotic purposes".

Likewise, article 174 sanctions the person who uses or facilitates email, chat, instant messaging, social networks, blogs, photoblogs, network games or any other electronic or telematic means (services and applications that use both computer systems and those of telecommunication) to offer sexual services with minors of eighteen years of age. This will be punished with a custodial sentence of seven to ten years [14].

The general procedure established after the complaint was also known.

The research allowed us to identify the scope of this issue in Ecuador and what needs to be improved.

\section{Results}

From the research and analysis of the link of Facebook and Whatsapp with cyberbullying obtained from the referenced scientific articles, it was known that social networks users post on the net photos and videos in public form that in a matter of minutes go viral, these publications are accompanied by location, from a known location, user information in the description that the cyber stalker uses to investigate, follow his victim, study it, know the sites he frequently visits, obtain intimate information and ultimately extort or threaten. Unlike Whatsapp where the user consciously sends intimate photos/videos without measuring the consequences.

Making to referring at this first point mentioned, an iterative pattern of how cyberstalkers operate could be evidenced and we have represented it in the following diagram to identify the problem, clarify the actions that originate it and change the result: 




Figure 4. Diagram of how cyberbullying cases arise. Source: The authors.

In addition, research in scientific articles and figures based on the report "Digital State Ecuador" of users by social network in Ecuador indicates that in the country the most used social network is Facebook, unlike other countries, such as in the Emirates United Arab Emirates (EUA) where the highest percentage of users on a social network is concentrated on WhatsApp. After this and also considering the statistical data provided by the INEC in its percentage of population with cellphones and social networks from 2012 to 2018 it is identified that a considerable number of minors have access and use social networks deliberately, being the main victims of this crime.

From the figures collected during the investigation we will take the following:

$\mathrm{Ca}$ : People in Ecuador who have their cell phone on. (Figure 2)

$\mathrm{Cr}$ : Cases of cyberbullying in Ecuador.

Figures from the National Statistics and Census Institute (INEC) and the United Nations Educational, Scientific and Cultural Organization (Unesco) indicate that 7\% of the population has suffered from cyberbullying [15].

$$
\mathrm{Cr}=\% \text { Cyberbullying } \times \mathrm{Ca}
$$

Cme : Cases of harassment by electronic means. (Figure 1)

$$
\text { Cme }=\Sigma \% \text { Victim of assault by electronic means } \times \mathrm{Cr}
$$

(Figures up to 2018).

$$
\begin{gathered}
C a=9402578 \\
C r=658180.46 \\
C m e=151381.51
\end{gathered}
$$

To estimate a ratio percentage; Inhabitants with cellphone activated - Reported cases of cyberbullying by electronic means will use the following formula:

$$
P_{r f}=\frac{C r \times 100 \%}{C m e} \times \frac{\text { Cme } \times 100 \%}{C a}=\frac{C m e}{C a}
$$

The result of this formula is $0.07 \%$.

According to the resulting percentage, it can be deduced that in Ecuador the number of cases reported is very low in relation to people who have cell phones activated and who may be victims of cyber-harassment.

This resulting percentage is not reported to citizens in television media, however it is observed daily in digital media and makes us think that it is evident that these cases 
are happening frequently and it is important to criminalize the conduct of cyberbullying, Since the commission of the same is more and more unquestionable every day, what makes of it a relevant conduct since it produces threat, with harmful results in the victim difficult to repair generating disastrous consequences for these people.

In order for this conduct to be criminalized, it must be committed through electronic means using social networks, and acts of contempt towards the individual must be committed in order to proceed to report and that legal action process is executed. This process is shown in the following diagram and is successful in some cases:

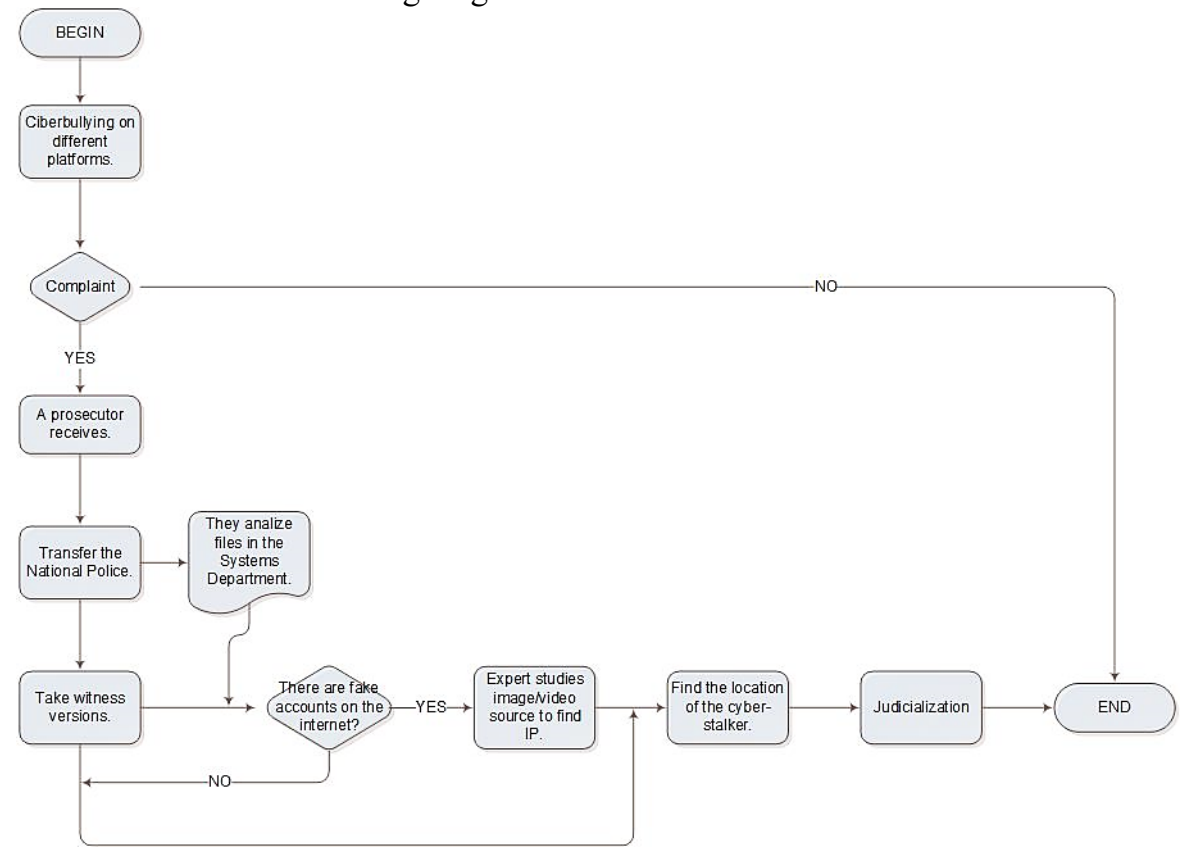

Figure 5. Criminal Process Diagram. Source: The authors.

Within the process of Judicialization it result determinant the reason that entailss to take into consideration articles 173 and 174 stipulated in the COIP to establish what type of computer crime has been committed and subsequently determine the process thereof but not penalized for the crime of cyberbullying in its different scenarios.

Currently there are different concepts associated with cyberbullying, these concepts have been classified by facts that have characteristics in common: cyberbullying, grooming, web beating, flame [16].

In Ecuador there are still no laws that go hand in hand with technological progress and that have a direct impact on these concepts; in the articles presented and analyzed it has been found that their content is very general.

The advance of information on social networks is a crop that cybercriminals often use to carry out illicit activities such as constant cyber-bullying, hacking, blackmail etc., criminal activities that go against the laws of each country. That is why we are constantly working internationally to combat this organized crime and to enforce the law. 


\section{Discussion}

Knowing the results of the investigation and all the information presented during the article, we note that the figures presented by the various institutions responsible for conducting censuses and statistics are far removed from the current situation in Ecuador with reference to the subject under discussion. The government through its ministries supports different organizations to create campaigns that prevent this crime but not to reform laws that help mitigate it, this causes people who are victims of this crime not to report the crime. According to the investigation, the two articles classified in the Comprehensive Organic Criminal Code are very general and allow cases to pass that have been reported, but not resolved by these very limited laws.

\section{Future Work and Conclusion}

\subsection{Futures Works}

Comprehensively analyze the laws that refer to computer crimes and harassment, described in the Constitution so that they can be reformed and even incorporated new ones in line with what is currently happening by linking society to technology.

Different types of cyberbullying, such as grooming and sexting, should also be investigated and analyzed, and specifically punished.

\subsection{Conclusions}

It is concluded after the research and analysis of the topic in question:

- Ecuador works hard and in conjunction with Government Organization (GO)s and Non-Governmental Organization (NGO)s to carry out campaigns to prevent cyberbullying, however, their communication media do not constantly broadcast or support this issue in society for that is examined.

- The lack of laws that mitigate cyberbullying and protect data on social media and other web platforms gives cyberbullies the freedom to commit their acts without clemency and mainly children who tend to keep these facts quiet.

- As cyberbullying is not typified, there is no exact regulation that penalizes the fact, therefore, the rights of the victim are affected, for this problematic it is propose to create a bill that make refers to cyberbullying in its different scenarios so that it is sent to the assembly and thus contrast the present thematic.

\section{Acknowledgments}

The authors thank to Universidad Politécnica Salesiana del Ecuador, to the research group of the Guayaquil Headquarters "Computing, Security and Information Technology for a Globalized World" (CSITGW) created according to resolution 142-06-2017-07-19 and Secretaría de Educación Superior Ciencia, Tecnología e Innovación (Senescyt). 


\section{References}

[1] «El ciberacoso es un problema en crecimiento que afecta hasta 1 de cada 10 niños en el mundo.,» EcuadorUniversitario.Com, 2019.

[2] M. ALI AL-GARADI, M. RASHID HUSSAIN, N. KHAN, G. MURTAZA, H. FRIDAY NWEKE, I. ALI, G. MUJTABA, H. CHIROMA, H. ALI KHATTAK y A. GANI, «Predicting Cyberbullying on Social Media in the Big Data Era Using Machine Learning Algorithms: Review of Literature and Open Challenges,» IEEE Access, vol. 7, nº 8720155, pp. 70701-70718, 2019.

[3] F. IQBAL, B. C. M. FUNG, M. DEBBABI, R. BATOOL y A. MARRINGTON, «Wordnet-Based Criminal Networks Mining for Cybercrime Investigation,» IEEE Access, vol. 7, n 8606047, pp. 22740-22755, 2019.

[4] G. R. Vera Mora y J. V. León Acurio, «CYBERBULLYING: UNA REALIDAD DE INTIMIDACIÓN EN LAS UNIDADES,» Atlante. Cuadernos de Educación y Desarrollo, 2017.

[5] A. Martinez, «Telefónica Movistar: La realidad del ciberacoso en Ecuador y cómo denunciarlo.,» Metro Ecuador, Quito, 2019.

[6] «Cómo prevenir el ciberacoso o ciberbullying.,» EL UNIVERSO, Guayaquil, 2019.

[7] Ghada M. Abaido (2020) Cyberbullying on social media platforms among university students in the United Arab Emirates, International Journal of Adolescence and Youth, 25:1, 407-420, DOI: 10.1080/02673843.2019.1669059..

[8] S. M. Toapanta Toapanta, F. G. Mendoza Quimi, L. M. Romero Lambogglia y L. E. Mafla Gallegos, «Impact on the Information Security Management due to the Use of Social Networks in a Public Organization in Ecuador,» Smart Innovation, Systems and Technologies, vol. 165, pp. 51-64, 4 Diciembre 2019.

[9] Huang, C. L., Zhang, S., \& Yang, S. C. (2020). How students react to different cyberbullying events: Past experience, judgment, perceived seriousness, helping behavior and the effect of online disinhibition. Computers in Human Behavior, 110 doi:10.1016/j.chb.2020.106338.

[10] G. Kashy-Rosenbaum y D. Aizenkot, «Exposure to cyberbullying in WhatsApp classmates ' groups and classroom climate as predictors of students' sense of belonging: A multi-level analysis of elementary, middle and high schools,» Children and Youth Services Review, vol. 108, nº 104614, pp. 2-10, 2020.

[11] N. Auemaneeku, A. Powwattana, E. Kiatsiri y N. Thananowan, «Investigating the mechanisms of theory of planned behavior on Cyberbullying among Thai adolescents,» Journal of Health Research, vol. 34, pp. 42-55, 2020.

[12] Oksanen, A., Oksa, R., Savela, N., Kaakinen, M., \& Ellonen, N. (2020). Cyberbullying victimization at work: Social media identity bubble approach. Computers in Human Behavior, 109 doi:10.1016/j.chb.2020.106363.

[13] INEC, «Tecnologías de la Información y Comunicaciones.,» 2017.

[14] El Diario.ec, «Ciberacoso, un dolor de cabeza para los padres,» El Dairio.ec, 15 Julio 2018.

[15] Gao, L., Liu, J., Wang, W., Yang, J., Wang, P., \& Wang, X. (2020). Moral disengagement and adolescents' cyberbullying perpetration: Student-student relationship and gender as moderators. Children and Youth Services Review, 116 doi:10.1016/j.childyouth.2020.105119.

[16] Instituto Nacional de Estadística y Censos, «INEC,» [En línea]. Available: https://www.ecuadorencifras.gob.ec/objetivos-politicas/. 